\title{
Aproveitamento de águas pluviais e o reúso de águas cinzas em edifícios residenciais de Brasília - parte 2: viabilidade técnica e econômica
}

\author{
SANT'ANA, Daniel ${ }^{1}$ \\ BOEGER, Louise ${ }^{2}$ \\ MONTEIRO, Lilian ${ }^{3}$ \\ 1Faculdade de Arquitetura e Urbanismo, Universidade de Brasília, Brasília, Brasil. dsantana@unb.br \\ ${ }^{2}$ Faculdade de Arquitetura e Urbanismo, Universidade de Brasília, Brasília, Brasil. louiseboeger@gmail.com \\ ${ }^{3}$ Faculdade de Arquitetura e Urbanismo, Universidade de Brasília, Brasília, Brasil. lilian@vilelamonteiro.com.br
}

\section{Resumo}

A viabilidade da implementação de sistemas de aproveitamento águas pluviais (AAP) e de reúso de águas cinzas (RAC) em edifícios residenciais é analisada e os resultados são apresentados em dois artigos. A primeira parte caracteriza os usos-finais do consumo doméstico de água de edificações residenciais de Brasília e identifica o potencial de redução no consumo de água promovido por diferentes sistemas AAP e RAC. A segunda parte aponta possíveis soluções para adaptação predial das tipologias residenciais de Brasília e faz uma avaliação financeira dos custos-benefícios para diferentes tipos de sistemas AAP e RAC. Em geral, resultados indicam que a adaptação predial voltada ao aproveitamento de águas pluviais em demandas externas é uma solução simples e rentável. Em alguns casos, reservatórios inferiores de água fria podem ser modificados para servir como cisternas de água pluvial, reduzindo custos de capital. Adaptação predial voltada ao aproveitamento de águas pluviais em demandas internas demonstrou ser uma solução inviável devido aos altos custos de reforma. Por outro lado, sistemas de reúso de águas cinzas em demandas internas promovem benefícios financeiros significativos, o que acaba compensando os custos de reforma. $O$ reúso de águas cinzas em demandas externas demonstrou ser uma alternativa inviável devido aos altos custos do sistema e aos baixos benefícios financeiros.

Palavras-Chave: Aproveitamento de águas pluviais; Reúso de águas cinzas; Adaptação predial; Análise custo-benefício.

\begin{abstract}
The feasibility of implementing rainwater harvesting (RWH) and greywater reuse (GWR) systems on residential multi-storey buildings is analysed and results are presented in two articles. The first part characterizes domestic water end-use consumption for typical residential building typology found in Brasilia, Brazil, and identifies potential water savings promoted by different RWH and GWR systems. The second part pinpoints possible solutions to adapt the existing residential building stock in Brasilia and carries out a financial assessment of the cost-benefits for different types of RWH and GWR systems. Overall, findings suggest that building adaptation for rainwater use in outdoor demands is a simple and cost-effective solution. In some cases, ground level or basement mains water storage tanks can be retrofitted to serve as rainwater cisterns, reducing capital costs. Building adaptation for rainwater use in indoor demands proved to be an unfeasible solution due to high refurbishment costs. On the other hand, indoor greywater reuse systems promote significant financial benefits, outweighing refurbishment costs. Outdoor greywater reuse proved to be an unfeasible option due to high system costs and low financial benefits.
\end{abstract}

Keywords: Rainwater harvesting; Greywater reuse; Building adaptation; Cost-benefit analysis. 


\section{Introdução}

Está comprovado que a exploração de fontes hídricas baseada em uma gestão focada na oferta de água para conciliar desequilíbrios de oferta vs demanda de água pelo represamento, desvio ou bombeamento de recursos naturais, pode resultar em sérios danos ambientais e desperdício econômico (HERRINGTON, 2006). A fim de reduzir a sobrecarga do consumo sobre os recursos hídricos, o uso de estratégias voltadas à conservação de água tem sido visto como uma estratégia eficaz na gestão da demanda de água. Segundo VICKERS (2001, p.5), estratégias de conservação de água são "ferramentas específicas (tecnologias) e práticas (alteração do comportamento)... que resultam no uso mais eficiente da água". A autora argumenta que o uso de tecnologias de conservação de água geralmente são mais confiáveis para a obtenção de economia e controle sobre o consumo de água.

Segundo Sant'Ana e Amorim (2007), o aproveitamento de água pluvial é um conceito simples, que ao invés de permitir que as águas da chuva provenientes da cobertura escoem pelos bueiros, elas são filtradas e armazenadas em uma cisterna para seu aproveitamento na irrigação, limpeza, lavagem de roupas, descarga sanitária e demais usos cujo requisito de potabilidade não seja necessário. Os mesmos usos não potáveis se aplicam ao reúso de águas cinzas (esgoto secundário proveniente de lavatórios, chuveiros, tanques e máquinas de lavar roupa). Para tanto, May (2009) recomenda um tratamento adequado para eliminar matéria orgânica e microrganismos patogênicos à saúde humana encontrados nessas águas servidas. Conforme estabelecido na Norma NBR 5626 (ABNT, 1998), ambos os sistemas de aproveitamento de água pluvial (AAP) e de reúso de águas cinzas (RAC) necessitam de uma rede predial de distribuição de água não potável distinta, evitando conexões cruzadas, e de dispositivos de separação atmosférica, para proteção sanitária da rede de água potável durante o processo de alimentação de água da concessionária no sistema predial de água não potável.

Ao considerar a possibilidade de adaptar o estoque de edificações residenciais existentes em Brasília para o aproveitamento de água pluvial ou o reúso de águas cinzas como fonte alternativa de abastecimento de água não potável, torna-se imprescindível uma avaliação técnica, econômica e ambiental para averiguar sua viabilidade. Diferentes estudos em países desenvolvidos avaliaram os custos e benefícios para diferentes sistemas AAP e RAC (e.g. MUSTOW et al., 1997; BREWER et al., 2001; ROEBUCK et al., 2010). No entanto, esses países contém uma realidade econômica favorável, diferente a de países em desenvolvimento. No Brasil, estudos verificaram o período de retorno de investimento (payback) de sistemas AAP e RAC para duas casas e três edifícios residenciais no Sul do país. Outro estudo realizou uma análise custo-benefício usando valor presente líquido para casas em João Pessoa (JÚNIOR et al., 2008). No entanto, há uma carência de informações referentes à viabilidade econômica no que se diz respeito às possíveis adaptações hidráulicas de edifícios residenciais existentes para a instalação de sistemas AAP e RAC, especialmente no que se refere à tipologia residencial de Lúcio Costa, em Brasília.

Com isso em mente, o presente artigo buscou verificar a adaptabilidade hidráulica de edifícios residenciais existentes para a instalação de sistemas AAP e RAC e identificar a viabilidade econômica de diferentes configurações hidráulicas para uma implementação estratégica no estoque de edifícios residenciais em Brasília. Para avaliar a viabilidade desses sistemas, torna-se fundamental verificar as economias anuais geradas pelo aproveitamento de águas pluviais e reúso de águas cinzas nas edificações. Com isso, o presente artigo dá continuidade à primeira parte do estudo "Aproveitamento de águas pluviais e o reúso de águas cinzas em edifícios residenciais de Brasília - parte 1: reduções no consumo de água", que faz a caracterização dos usos-finais do consumo doméstico de água em edificações residenciais de Brasília e identifica o potencial de redução do consumo de água promovido pelo aproveitamento de águas pluviais e reúso de águas cinzas para diferentes cenários de demandas não potáveis.

\section{Metodologia}

Como ponto de partida, foram realizadas vistorias in loco nas redes de instalações hidráulicas de água fria (potável), água pluvial e de esgoto predial em 19 edifícios residenciais dos bairros da Asa Sul e Asa Norte em Brasília. Com isso, as características típicas das instalações hidráulicas prediais foram agregadas em um modelo representativo para servir de base na avaliação dos custos e benefícios financeiros de diferentes sistemas AAP e RAC. Baseado nessas redes hidráulicas características, buscou-se alternativas de simples intervenção e baixo custo de reforma para adaptação predial voltada ao aproveitamento de águas pluviais e reúso de águas cinzas em lavagem de pisos e irrigação (Cenário 1), descarga sanitária (Cenário 2) e lavagem de roupas (Cenário 3). O modelo representativo serviu como base para a composição hidráulica de diferentes sistemas AAP e RAC e para o dimensionamento de tubulações, reservatórios e demais equipamentos hidráulicos. Com isso, foi possível 
quantificar o material hidráulico e orçar os custos de capital relativos ao sistema, reforma e mão de obra. Custos operacionais foram determinados conforme o consumo de energia, manutenção e troca de componentes do sistema, conforme sua vida útil (Tabela 1).

Tabela 1: Vida útil de componentes hidráulicos.

\begin{tabular}{lll}
\hline $\begin{array}{l}\text { Componente Hidráulico } \\
\text { do Sistema }\end{array}$ & $\begin{array}{l}\text { Vida Útil } \\
\text { Indicada* }\end{array}$ & $\begin{array}{l}\text { Vida Útil } \\
\text { Estimada }\end{array}$ \\
\hline Tubulações em PVC & $>20$ anos & 30 anos \\
Bombas de Recalque & $5-10$ anos & 7,5 anos \\
Filtros Pluviais & $10-15$ anos & 12,5 anos \\
Válvulas Solenóide & $5-10$ anos & 7,5 anos \\
Torneiras Bóia & $10-15$ anos & 12,5 anos \\
Chaves Bóia & $10-15$ anos & 12,5 anos \\
Reservatórios & $>20$ anos & 30 anos \\
Unidade de Tratamento & $10-50$ anos & 30 anos \\
\hline
\end{tabular}

*Fonte: LEGGETT et al. (2001)

Considerando o potencial de redução do consumo de água encontrado na primeira parte do estudo, os benefícios financeiros dos sistemas AAP e RAC foram identificados por meio de três métodos de análise custo-benefício diferentes: (i) payback simples, (ii) valor presente líquido e (iii) custo incremental médio.

Supondo que para o público geral, o principal incentivo para investir em tecnologias de conservação de água seja para gerar economias financeiras e poupar dinheiro, uma análise do período de retorno financeiro foi realizada a fim de verificar quais sistemas AAP e RAC eram mais propensos a ser investido pelo público geral. A principal vantagem do método de análise por payback simples, é que ele fornece uma estimativa de fácil compreensão dos benefícios gerados por um sistema a partir do ponto de vista do cliente. O payback simples identifica o período de tempo (geralmente medido em anos), que leva para um investimento gerar benefícios financeiros suficientes para se pagar (Equação 1). Nesse caso, o menor período de retorno é considerado o meIhor investimento, e períodos de retorno acima da vida útil do sistema são considerados opções inviáveis para investimento.

$P B S=\frac{K}{\left[\sum_{1}^{12}\left(E_{a} \times C_{a}\right)\right]-C_{o}}$

$P B S=$ Payback simples (anos)

$K=$ Custo capital de investimento $(R \$)$

$E_{a}=$ Economia de água mensal $\left(\mathrm{m}^{3}\right)$

$C_{a}=$ Custo de água mensal $\left(\mathrm{R} \$ / \mathrm{m}^{3}\right)$

$C_{o}=$ Custo operacional anual $(\mathrm{R} \$)$

Porém, o método de análise por payback simples não leva em conta a distribuição de custos e benefícios ao longo do tempo e ignora a economia financeira total gerada durante a vida útil de uma tecnologia de conservação de água. Contudo, uma análise do valor presente líquido do ciclo de vida de sistemas AAP e RAC foi realizada a fim de levar em conta todos os custos e benefícios relevantes durante sua vida útil ( $t=30$ anos), incluindo os ajustes do valor no tempo, t. A análise do valor presente do ciclo de vida permitiu uma comparação dos benefícios financeiros adquiridos ao longo da vida útil dos sistemas AAP e RAC, usando uma taxa de juros de $3 \%$, determinada pela média da taxa referência (TR) e taxa de juros de longo prazo (TJLP) de Junho 2011 a Junho 2012 (Equação 2). Os valores referentes aos benefícios anuais ( $\mathrm{R} \$$ /ano) foram calculados a partir do potencial de redução de consumo de água, encontrado na primeira parte do estudo, multiplicado pela alíquota cobrada em blocos tarifários por faixa de consumo pela concessionária local. O valor utilizado para alíquota da água, referente à última faixa de consumo, entre 36 e 50 $\mathrm{m}^{3} / \mathrm{mês}$, foi de $\mathrm{R} \$ 7,98$ por $\mathrm{m}^{3}$ de água consumida. A faixa de consumo foi determinada dividindo o consumo médio mensal das edificações analisadas pelo número médio de apartamentos.

$V P L=-K_{0}+\sum_{t=0}^{n} \frac{B_{t}-C_{t}}{(1+i)^{t}}$

$V P L=$ Valor presente líquido $(R \$)$

$K_{0}=$ Custo capital no ano zero $(\mathrm{R} \$)$

$B_{t}=$ Benefícios no ano, t (R\$/ano)

$C_{t}=$ Custos no ano, $\mathrm{t}(\mathrm{R} \$ / \mathrm{ano})$

$i=$ Taxa de juro anual (\%)

$n=$ Vida útil (anos)

$C I M=-\left[\frac{K-B+C_{o}}{E_{a}}\right]$

$C / M=$ Custo incremental médio $\left(\mathrm{R} \$ / \mathrm{m}^{3}\right)$

$K=$ VPL do custo capital $(\mathrm{R} \$)$

$B=$ VPL dos benefícios $(\mathrm{R} \$)$

$C_{o}=$ VPL dos custos operacionais $(\mathrm{R} \$)$

$E_{a}=$ Economia de água total $\left(\mathrm{m}^{3}\right)$

Certamente, ao verificar resultados do valor presente líquido do ciclo de vida, quanto maior o valor presente líquido, maior será o benefício financeiro gerado por uma determinada tecnologia de conservação de água ao longo de sua vida útil. Porém, esse método pode apresentar limitações ao comparar diferentes tecnologias de conservação de água, com diferentes expectativas de vida útil e de diferentes escalas. Portanto, uma análise do custo incremental médio foi utilizado para comparar a rentabilidade de tecnologias de diferentes grandezas, nivelando resultados em um parâmetro de comparação de benefício financeiro por volume de água economizada, dentro do mesmo horizonte de tempo ( $\mathrm{t}=30$ anos). Com 
Figura 1: Fluxograma das redes de água fria, águas pluviais e esgoto sanitário das edificações residenciais.

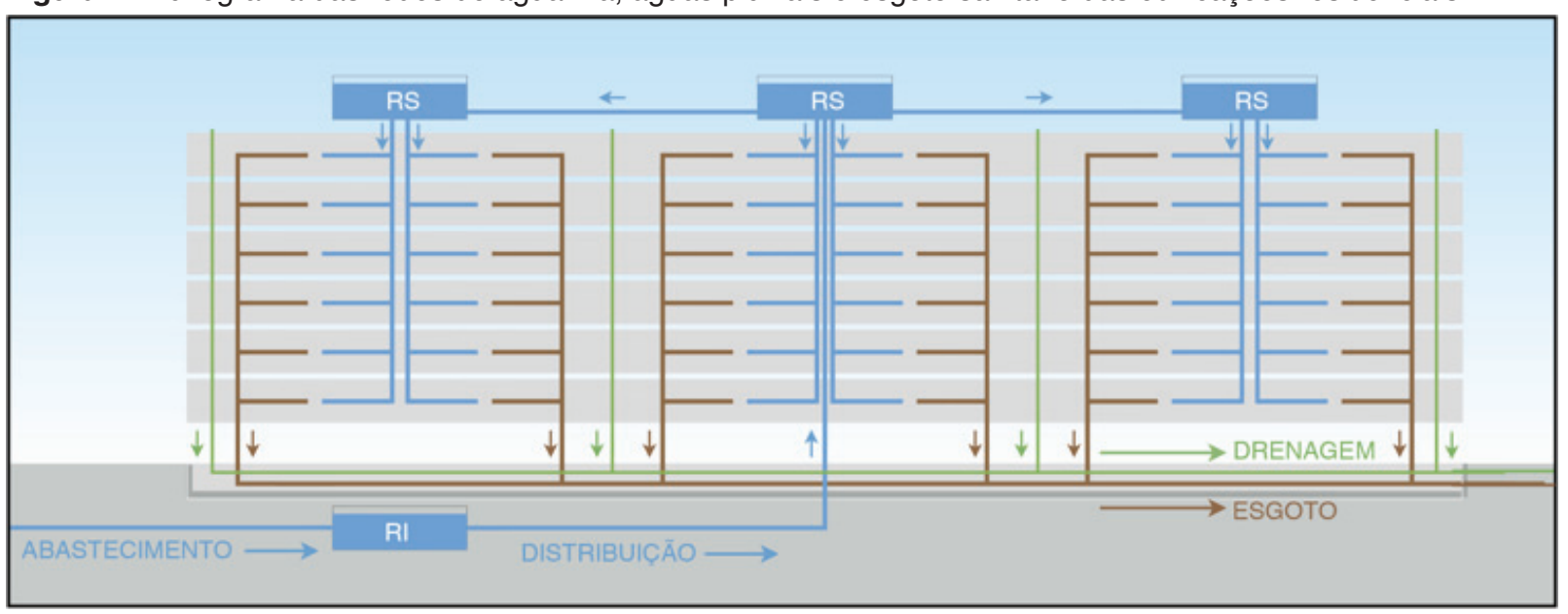

isso, indicadores do valor econômico da conservação de água, em $\mathrm{R} \$ / \mathrm{m}^{3}$ foram gerados para ambos os sistemas AAP e RAC.

O custo incremental médio pode ser identificado como o valor presente líquido de uma série de custos futuros de capital e de operação para uma determinada tecnologia que esteja gerando benefícios financeiros, dividido pela economia de água total para um determinado horizonte de tempo (Equação 3).

\section{Características das Instalações}

Em relação às instalações hidráulicas, percebeuse uma constante no que diz respeito à existência de mais de um reservatório superior de distribuição de água fria em todos os edifícios visitados. Em geral, verificou-se que havia um reservatório superior de água por prumada de elevadores. A maioria dos edifícios possui também um reservatório inferior, que armazena a água fria vinda do cavalete de entrada antes de ser bombeada para o reservatório superior para distribuição (Figura 1). Porém, foi constatado que muitos dos reservatórios inferiores encontram-se desativados e a alimentação de água é direta para o reservatório superior, sem recalque. Nesse caso, esses reservatórios desativados podem ser adaptados e usados como cisternas para armazenagem de água pluvial.

Na maioria das edificações analisadas, a coleta de águas pluviais é realizada através de tubos de queda posicionados em uma linha longitudinal no centro da cobertura do edifício, constituída de telhado de água furtada em telha de fibrocimento. A água pluvial coletada é desviada para um dos lados do edifício e passa por caixas de inspeção no nível térreo antes de seguir para o sistema de drenagem urbana.
Todas as edificações analisadas apresentaram tubulações de esgoto secundário provenientes de lavatórios e chuveiros conectadas a tubulações de esgoto primário proveniente de descargas sanitárias nos banheiros. No entanto, percebeu-se que $80 \%$ das edificações apresentavam uma configuração hidráulica cuja tubulação de esgoto secundário proveniente da lavanderia era isolada dos demais efluentes.

Vistorias hidráulicas apontaram dois tipos de distribuição interna das tubulações para abastecer as descargas sanitárias em banheiros: (i) integradas; ou (ii) isoladas. A rede de tubulação integrada (Figura 2a) faz uso de um único trajeto para abastecer todos os pontos de uso de água no banheiro. Já a rede de tubulação isolada (Figura $2 b$ ), apresentou uma coluna d'água distinta para alimentação de água em válvulas de descargas sanitárias.

No que se diz respeito à rede de distribuição de água para lavagem de roupas, todas as edificações analisadas apresentaram apenas uma coluna d'água voltada para a alimentação de água em pontos de uso na cozinha (torneira da pia, filtro e máquina de lavar louças) e na área de serviço (tanque e máquina de lavar roupas).

\section{Adaptação Predial}

\subsection{Aproveitamento de Águas Pluviais}

Para a análise do sistema AAP voltado à lavagem de pisos e irrigação (Cenário 1), foram considerados dois modelos de adaptação: i) Modelo 1 Edifícios com reservatório disponível; e ii) Modelo 2 - Edifícios com nova cisterna. No Modelo 1, considerou-se o uso dos reservatórios inferiores existentes que não estejam sendo utilizados (Figura 3a). O Modelo 2 considerou-se a instalação de uma cisterna de água pluvial comercialmente disponível (Figura 3b). Para ambos os casos, a adaptação predial provou ser simples, 
Figura 2: Configuração hidráulica integrada (a) e isolada (b) na alimentação de água dos banheiros

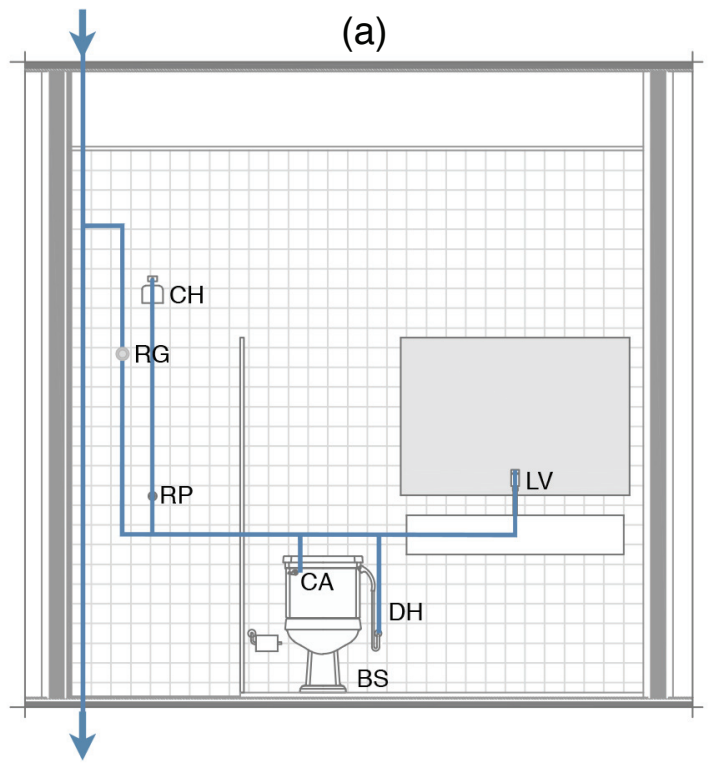

aproveitando a rede coletora de água pluvial existentes nas edificações, por meio de uma simples intervenção, direcionando as águas pluviais para um filtro antes de armazená-la em uma cisterna para seu aproveitamento não potável. Para o aproveitamento de águas pluviais em lavagem de pisos e irrigação (Cenário 1) as águas pluviais armazenadas podem ser bombeadas para as torneiras de uso geral, após adaptação da rede de distribuição existente.

A adaptação predial para o aproveitamento de águas pluviais em descargas sanitárias (Cenário 2) em edificações com uma rede de distribuição integrada exigem um maior nível de reforma para adequar suas tubulações hidráulicas nos banheiros, sendo necessário recompor o traçado hidráulico de maneira que evite conexões cruzadas. Essa solução, além de possuir custos adicionais referentes à reforma e acabamento, sua reforma gera um incômodo para os moradores e, portanto, tal

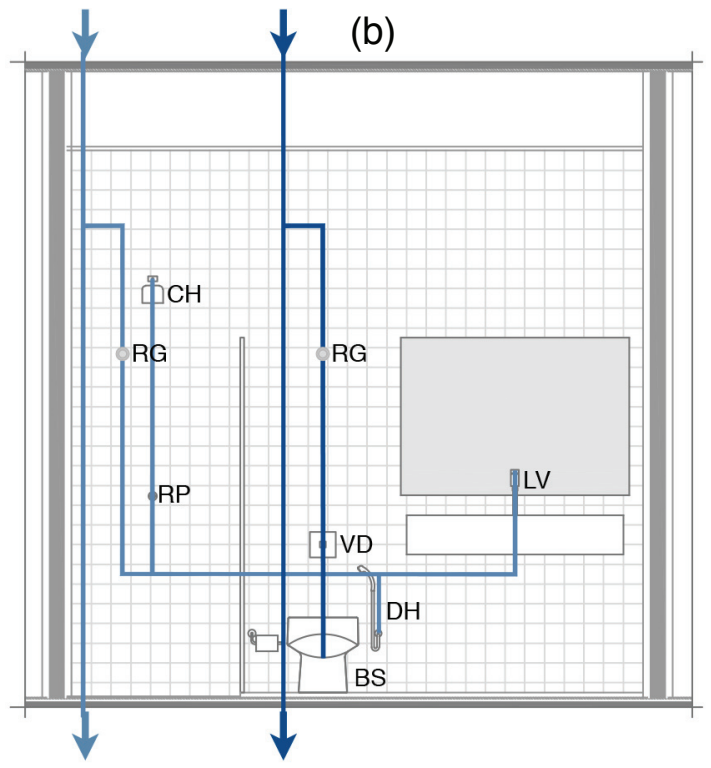

adaptação foi desconsiderada para análise custo-benefício. Já o aproveitamento de águas pluviais em descargas sanitárias (Cenário 2) em edificações com uma rede de distribuição isolada para válvulas de descarga, permite uma adaptação hidráulica simples, em nível de barrilete, evitando grandes custos relacionados à reforma em banheiros e permitindo o uso de água não potável em descargas sanitárias. Nesse caso, essa adaptação predial foi considerada para análise custo-benefício.

Para a adaptação predial voltada ao aproveitamento de águas pluviais em lavagem de roupas (Cenário 3), seria necessário desconectar a tubulação de água fria da cozinha, e criar uma nova coluna d'água não potável para alimentar os pontos de uso na lavanderia. Tal adaptação predial foi considerada inviável, por apresentar um alto grau de reforma, elevando os custos de reforma e gerando incômodos aos moradores.

Figura 3: Modelo 1: para adaptação de edifícios com reservatório inferior disponível (a); e Modelo 2: para adaptação de edifícios sem reservatório inferior disponível (b).

(a)

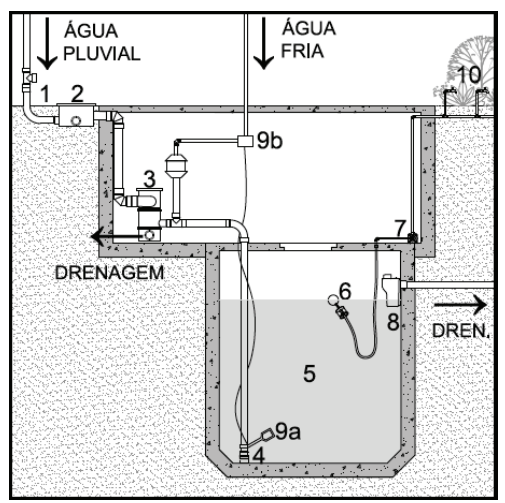

(b)

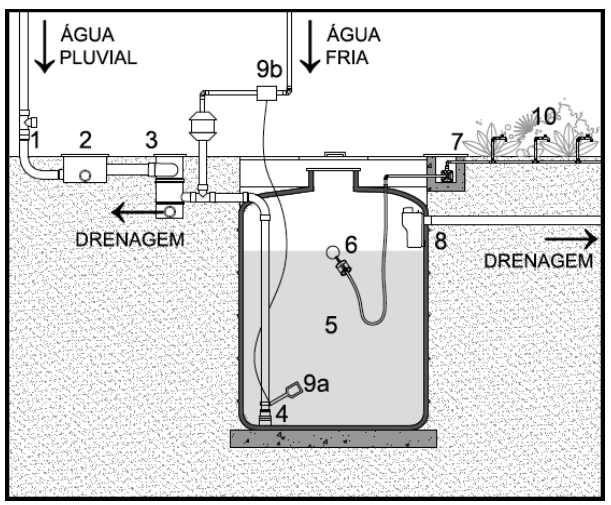

1. Tê de inspeção

2. Caixa de inspeção

3. Filtro pluvial

4. Freio d'água

5. Reservatório existente ou

cisterna nova enterrada

6. Filtro de sucção

7. Bomba de recalque

8. Sifão-ladrão

9a. Boia de nível

9b. Válvula solenóide

10. Torneira de uso geral 


\subsection{Reúso de Águas Cinzas}

Pela configuração hidráulica do esgotamento sanitário dos banheiros, seria necessário separar as tubulações de esgoto secundário (lavatório, chuveiro e banheira) das tubulações de esgoto primário (vaso sanitário). Por um lado, essa intervenção poderia ocorrer sem grandes reformas dentro dos banheiros, porém, muitos dos edifícios analisados não apresentaram shafts verticais para passar com um novo tubo de queda destinado à coleta de águas cinzas dos banheiros. Isso poderia acarretar em grandes modificações para adaptação predial.

No entanto, foram identificados uma série de redes coletoras de esgoto secundário distintas, proveniente de tanques e máquinas de lavar roupas. Nesse caso, os tubos de queda transportam as águas servidas na lavanderia para uma caixa de sabão em nível térreo e, antes que essas águas cinzas se misturem com a rede coletora de esgoto primário, a adaptação pelo seu desvio para uma unidade de tratamento provou ser de baixo custo e de intervenção.

Após tratamento, as águas cinzas podem ser reutilizadas diariamente em fins não potáveis, conforme os cenários. Para o primeiro cenário, as águas cinzas tratadas podem ser armazenadas em um reservatório inferior para reúso em lavagem de pisos e irrigação com o auxílio de uma bomba de recalque. Para os Cenários 2 e 3, após tratamento, as águas cinzas podem ser bombeadas para um dos reservatórios superiores existentes, para uma alimentação indireta dos pontos de uso não potável. As mesmas considerações para a adaptação da rede de distribuição de água nos Cenários 2 e 3 discutidos no item anterior, se aplicam ao reúso de águas cinzas em descarga sanitária e lavagem de roupas.

\section{Análise Custo-Benefício}

Em termos de adaptabilidade, tanto o Cenário 1 (lavagem de pisos e irrigação) quanto o Cenário 2 (descarga sanitária) se mostraram soluções viáveis para a instalação de sistemas AAP e RAC nas edificações residenciais de Brasília. Para tanto, a análise custo-benefício de ambos sistemas AAP e RAC limitou-se aos Cenários 1 e 2.

\subsection{Aproveitamento de Águas Pluviais}

As Tabelas 2 e 3, apresentam os resultados da análise custo-benefício para combinações entre os dois modelos de adaptação propostos, referentes a edifícios com reservatório existente (Modelo 1) e edifícios com nova cisterna (Modelo 2) para diferentes áreas de coleta $(200,500$ e $1000 \mathrm{~m} 2$, conforme capacidade de tratamento de filtro pluvial, o que corresponde a aproximadamente 1/5, 1/2 e toda a área de cobertura dos edifícios analisados.

Todas as edificações analisadas contém uma rede de coleta de água pluvial, portanto, custos relativos às suas instalações não foram levadas em consideração. Os custos de filtros pluviais variam de acordo com sua capacidade de filtragem, segundo área máxima de coleta de água pluvial. Existem filtros comercialmente disponíveis específicos para sistemas AAP que atendem a áreas máximas de coleta de 200, 500 e 1500 $\mathrm{m}^{2}$. Quanto maior a área máxima de coleta, maior o custo do filtro. Os custos com cisternas para armazenamento foram computados apenas para o Modelo 2, visto que o Modelo 1 prevê o armazenamento da água pluvial filtrada em reservatórios existentes em desuso. Os custos relativos à rede de distribuição de água não potável foram considerados iguais para ambos os Modelos.

Foram realizadas análises econométricas para diferentes capacidades de armazenagem de águas pluviais, de $5 \mathrm{~m} 3$ a $25 \mathrm{~m} 3$, baseados nos volumes de cisternas comercialmente disponíveis. Para efeito de comparação entre sistemas, foram selecionados os volumes de cisterna que apresentaram os maiores benefícios financeiros para cada área de coleta em ambos os modelos. Em ambos os Cenários 1 e 2, resultados demonstram que ao utilizar os reservatórios inferiores como cisternas de águas pluviais, os custos relativos à instalação de uma cisterna são descontados do custo capital

Tabela 2: Análise custo-benefício de sistemas AAP e RAC para o Cenário 1.

\begin{tabular}{|c|c|c|c|c|c|c|c|c|}
\hline $\begin{array}{l}\text { Tipo de } \\
\text { Sistema } \\
\end{array}$ & $\begin{array}{l}\text { Área Coleta } \\
\left(m^{2}\right)\end{array}$ & $\begin{array}{l}\text { Cisterna } \\
\left(\mathrm{m}^{3}\right)\end{array}$ & $\begin{array}{l}\text { Custo Cap. } \\
(R \$)\end{array}$ & $\begin{array}{l}\text { Custo 0p. } \\
\text { (R\$/ano) }\end{array}$ & $\begin{array}{l}\text { Benefícios } \\
\text { (R\$/ano) }\end{array}$ & $\begin{array}{l}\text { PBS } \\
\text { (anos) }\end{array}$ & $\begin{array}{l}\text { VPL* } \\
(R \$)\end{array}$ & $\begin{array}{l}\mathbf{C I M}^{*} \\
\left(R \$ / m^{3}\right) \\
\end{array}$ \\
\hline AAP & 200 & 25 & 2.903 & 26 & 630 & 5 & 6.923 & 2,92 \\
\hline \multirow[t]{2}{*}{ (Modelo 1) } & 500 & 25 & 3.657 & 26 & 646 & 6 & 6.459 & 2,66 \\
\hline & 1000 & 25 & 9.958 & 26 & 646 & 16 & 158 & 0,07 \\
\hline$\overline{\mathrm{AAP}}$ & 200 & 15 & 7.953 & 26 & 551 & 15 & 425 & 0,21 \\
\hline \multirow[t]{2}{*}{ (Modelo 2) } & 500 & 15 & 8.707 & 26 & 630 & 14 & 1.119 & 0,47 \\
\hline & 1000 & 10 & 14.128 & 26 & 646 & 23 & -4.012 & $-1,65$ \\
\hline$\overline{\mathrm{RAC}}$ & N.A. & N.A. & 34.151 & 570 & 646 & 449 & -33.278 & $-13,69$ \\
\hline
\end{tabular}


SANT'ANA, D.; BOEGER, L.; VILELA, L. Aproveitamento de água pluvial e o reúso de águas cinzas em edifícios residenciais de Brasília - parte 2: viabilidade técnica e econômica. Paranoá, Brasília, nº 10, p. 85-94, 2013.

Tabela 3: Análise custo-benefício de sistemas AAP e RAC para o Cenário 2.

\begin{tabular}{lllllllll}
\hline $\begin{array}{l}\text { Tipo de } \\
\text { Sistema }\end{array}$ & $\begin{array}{l}\text { Área Coleta } \\
\left(m^{2}\right)\end{array}$ & $\begin{array}{l}\text { Cisterna } \\
\left(m^{3}\right)\end{array}$ & $\begin{array}{l}\text { Custo Cap. } \\
(R \$)\end{array}$ & $\begin{array}{l}\text { Custo Op. } \\
(R \$ / \text { ano })\end{array}$ & $\begin{array}{l}\text { Benefícios } \\
(R \$ / a n o)\end{array}$ & $\begin{array}{l}\text { PBS } \\
(\text { anos })\end{array}$ & $\begin{array}{l}\text { VPL }^{*} \\
(R \$)\end{array}$ & $\begin{array}{l}\text { CIM }^{*} \\
\left(R \$ / m^{3}\right)\end{array}$ \\
\hline AAP & 200 & 25 & 2.903 & 394 & 1.963 & 1,9 & 31.118 & 4,22 \\
$($ Modelo 1$)$ & 500 & 25 & 3.657 & 394 & 4.908 & 0,8 & 83.823 & 4,54 \\
& 1000 & 25 & 9.958 & 394 & 7.725 & 1,4 & 128.663 & 4,43 \\
\hline AAP & 200 & 25 & 12.088 & 394 & 1.963 & 6,3 & 21.933 & 2,97 \\
$($ Modelo 2$)$ & 500 & 25 & 12.842 & 394 & 4.908 & 2,6 & 74.638 & 4,05 \\
& 1000 & 25 & 19.143 & 394 & 7.725 & 2,5 & 119.478 & 4,11 \\
\hline RAC & N.A. & N.A. & 36.299 & 1.433 & 14.485 & 2,8 & 189.678 & 3,48 \\
\hline (t=30 anos $)$ & & & & & & & &
\end{tabular}

de investimento. Consequentemente, edifícios com reservatórios inferiores disponíveis para adaptação predial (Modelo 1) se tornam opções mais rentáveis.

Para o Cenário 1, observou-se, que a área de coleta equivalente a $1000 \mathrm{~m} 2$ não é indicada para ambos os modelos, pois o custo dos filtros pluviais para áreas de coleta acima de $500 \mathrm{~m} 2$ acabam elevando o custo capital do sistema. O fato que os benefícios gerados por ambas as áreas de coleta não ultrapassam $\mathrm{R} \$ 646$ ao ano, não justifica o uso de uma área de coleta superior a $500 \mathrm{~m}^{2}$. Como podemos observar na Tabela 2, resultados do valor presente líquido (VPL) e do custo incremental médio (CIM) para o Modelo 1 são muito baixos e, para o Modelo 2, esse valor é negativo, sugerindo que o sistema AAP nunca irá gerar benefícios suficientes para cobrir custos de capital.

Já os resultados para o Cenário 2 demonstram que os sistemas AAP se mostraram economicamente viáveis, embora não atendam a demanda total de água para descarga sanitária, como visto na primeira parte do estudo. Nesse caso, como a demanda é superior à oferta de água da chuva, mesmo contando com toda a área de cobertura, quanto maior a área de coleta, maior a economia de água e mais benefícios financeiros o sistema será capaz de gerar. Nesse sentido, dentre as propostas, a área de coleta de $1000 \mathrm{~m} 2$ é a que gera maior economia ao longo da vida útil do sistema. Os benefícios são de uma grandeza tão superior ao custo capital que a necessidade ou não de uma nova cisterna representa pouca variação no lucro final do investimento.

\subsection{Reúso de Águas Cinzas}

Os custos relativos à adaptação predial para o reúso de águas cinzas em ambos os cenários, podem chegar a doze vezes mais do que a adaptação predial para o aproveitamento de águas pluviais. No Cenário 1, os altos custos de investimento não justificam o benefício gerado pelo sistema. Como podemos observar na Tabela 1, os custos operacionais do sistema RAC é muito elevado, se aproximando dos benefícios gerados pelo reúso de águas cinzas. Além dos valores negativos do valor presente líquido e do custo incremental, a inviabilidade do sistema pode ser deparada no seu período de retorno de investimento, equivalente a 449 anos.

Já no Cenário 2, os custos de investimento são pagos pelo alto grau de benefício financeiro gerado pelo sistema RAC. Nesse caso, o sistema RAC é capaz de suprir $100 \%$ da demanda anual de água para descargas em vasos sanitários, o que gera, consequentemente, economias de $\mathrm{R} \$ 14.485$ ao ano, contribuindo para um retorno financeiro de curto prazo (3 anos). Resultados do valor presente líquido demonstram que, caso uma edificação resolva investir em um sistema de reúso de águas cinzas para descargas sanitárias, os moradores receberão um lucro financeiro equivalente a $\mathrm{R} \$ 153.379$ dentro de sua vida útil estimada de 30 anos.

\section{Conclusão}

O presente artigo avaliou a viabilidade técnica e econômica da adaptação predial voltada ao aproveitamento de águas pluviais e reúso de águas cinzas para lavagem de pisos e irrigação (Cenário 1), descarga sanitária (Cenário 2) e lavagem de roupas (Cenário 3 ) em edificações residenciais de Brasília.

Baseado nas características das instalações hidráulicas típicas das edificações residenciais de Brasília, verificou-se possíveis intervenções hidráulicas para adaptação predial ao uso não-potável de água em torneiras de uso geral, descargas sanitárias e lavanderia. $\mathrm{O}$ primeiro cenário provou ser de simples adaptação predial, com pequenas intervenções na rede hidráulica existente. No que se diz respeito ao Cenário 2, apenas as configurações hidráulicas isoladas de alimentação de água em válvulas de descargas foram consideradas viáveis para adaptação predial por não 
exigirem reformas dentro dos banheiros, apenas uma simples intervenção nas tubulações de alimentação existentes em nível de barrilete, associado ao uso de um dos reservatórios superiores existentes para acumulo diário de água não potável. Por conter apenas uma única coluna d'água para alimentação de água na cozinha (pia, filtro e máquina de lavar louça) e área de serviço (tanque e máquina de lavar roupas), a adaptação predial para o aproveitamento de águas pluviais ou reúso de águas cinzas em lavagem de roupas demonstrou ser inviável pelo alto nível de reforma necessária. Para tanto o Cenário 3 foi descartado da análise custo-benefício.

Todas as edificações apresentaram uma rede coletora de águas pluviais existente e, para o armazenamento dessa água, foi identificado que em muitos casos, os reservatórios inferiores encontravam-se desativados, e que eles poderiam servir de cisterna. Para a coleta de águas cinzas, verificou-se tubos de quedas distintos, de esgoto secundário proveniente de tanques e máquinas de lavar roupas. Essa tubulação de águas cinzas das lavanderias podem ser adaptadas em nível térreo e ser direcionada para uma unidade de tratamento, antes de se misturar com demais esgotos prediais.

Baseado em um critério de avaliação econômica composta por payback simples, para verificar o período de retorno de investimento, valor presente líquido, para verificar os benefícios financeiros incorridos ao longo da vida útil do sistema, e do custo incremental médio, que fornece indicadores em $\mathrm{R} \$ / \mathrm{m}^{3}$ de água economizada para comparação dos benefícios de diferentes tecnologias de conservação de água, verificou-se a viabilidade econômica de diferentes sistemas AAP e RAC para os Cenários 1 e 2.

Para o Cenário 1, a melhor alternativa foi a instalação de um sistema AAP para uma área de coleta equivalente a $200 \mathrm{~m}^{2}$, que utilize um reservatório inferior existente (Modelo 1) com volume de $25 \mathrm{~m}^{3}$ para o armazenamento das águas pluviais. Resultados indicam que seu custo de investimento $(\mathrm{R} \$ 2.903)$ se paga em 5 anos, promovendo benefícios anuais equivalentes a $\mathrm{R} \$ 630$. Ao longo de sua vida útil (30 anos), o sistema haverá gerado benefícios com um valor presente líquido de $\mathrm{R} \$ 6$.923. Já para o Cenário 2, a alternativa mais rentável foi a instalação de um sistema RAC. Apesar do seu alto custo de investimento (R\$36.299), o sistema gera grandes benefícios anuais equivalentes a $\mathrm{R} \$ 14.485$, promovendo um retorno financeiro de curto prazo (3 anos), e lucros que podem chegar a $\mathrm{R} \$ 189.678$ em 30 anos.
Valores de custo incremental médio indicam que, em geral, sistemas AAP demonstraram ser alternativas mais viáveis para adaptação predial por apresentarem custos de investimento menores. No todo, a instalação de sistemas AAP em descarga sanitária, com área de coleta de $500 \mathrm{~m}^{2}$, utilizando um reservatório inferior existente para armazenar $25 \mathrm{~m}^{3}$ de água pluvial, provou ser a melhor opção de investimento, promovendo benefícios equivalentes a $\mathrm{R} \$ 4,54$ por $\mathrm{m}^{3}$ de água economizada.

É importante ressaltar que a seleção de uma tecnologia de conservação de água não deve se basear apenas em seus benefícios financeiros. No processo de tomada de decisão, é preciso considerar também os benefícios ambientais promovidos pela redução dos impactos no ciclo da água. Porém, presumindo que para o público geral, o principal incentivo para investir em tecnologias de conservação de água seja para gerar economias financeiras e poupar dinheiro, torna-se imprescindível por parte do governo, promover incentivos fiscais e financeiros para fomentar a implementação de políticas públicas destinadas ao controle da demanda urbana de água para uma gestão estratégica voltada à preservação dos recursos naturais.

\section{Agradecimentos}

Os autores agradecem o financiamento cedido pelo Programa de Iniciação Científica (ProlC/ UnB/ CNPq).

\section{Referências}

ABNT. NBR 5626: instalação predial de água fria. Rio de Janeiro: Associação Brasileira de Normas Técnicas, 1998. 41p.

Brewer, D.; Brown, R.; Stanfield, G. Rainwater and greywater in buildings: project report and case studies. Technical Note TN 7/2001. Berkshire: BSRIA, 2001. 105p.

GHISI, E.; FERREIRA, D. F. Potential for potable water savings by using rainwater and greywater in a multi-storey residential building in southern Brazil. Building and Environment, v.42 n. 7, p.2512-2522. 2007.

GHISI, E.; OLIVEIRA, S. M. Potential for potable water savings by combining the use of rainwater and greywater in houses in southern Brazil. Building and Environment, v. 42 n. 4, p.17311742. 2007.

HERRINGTON, P.R. The economics of water demand management. In: BUTLER, D.; MEMON 
F.A. (ed). Water Demand Management. Londres: IWA Publishing, 2006. p. 236-279.

Júnior, G. B. A.; Dias, I. C. S.; Gadelha, C. L. M. Viabilidade econômica e aceitação social do aproveitamento de águas pluviais em residências na cidade de João Pessoa. Ambiente Construído, v.8 n.2, pp.85-98. 2008.

LEGGETT, D.; BROWN, R.; BREWER, D.; HOLLIDAY, E. Rainwater and greywater use in buildings: decision-making for water conservation. London: CIRIA, 2001.

MAY, S. Caracterização, tratamento e reúso de águas cinzas e aproveitamento de águas pluviais em edificações. (2008). 222 f. Tese (Doutorado) - Departamento de Engenharia Hidráulica e Sanitária. Escola Politécnica da Universidade de São Paulo. São Paulo, 2009.

Mustow, S.; Grey, R.; Smerdon, T.. Water conservation: implications of using recycled greywater and stored rainwater in the UK. Berkshire: BSRIA, 1997. 84p.

SANT'ANA, D.; AMORIM, C. N. D. Reúso de água em edificações: premisas e perspectivas para o contexto brasileiro. Sistemas Prediais, São Paulo, v.2, n.1, Setembro, p.32- 37. 2007.

VICKERS, A. Handbook of water use and conservation. Amherst: Water Plow Press, 
